\title{
Aptamer based rGO-AuNPs Electrochemical Sensors and its Application for Detection of Salmonella Anatum in Food
}

\author{
Mingyan Chai \\ Department of Pharmacy and Biotechnology, Zibo Vocational Institute, Zibo 255314, China \\ E-mail: mingyan_chai@163.com
}

Received: 3 Sepyember 2021 / Accepted: 29 October 2021 / Published: 6 December 2021

\begin{abstract}
Foodborne pathogenic bacteria can cause food poisoning or infection. Salmonella is an aerobic or partly anaerobic gram-negative bacterium that enters the body with food, invades the intestine and releases large amounts of endotoxin. The endotoxin acts as a pyrogen that leads to an increase in body temperature and acts on the intestinal mucosa to trigger systemic inflammation and toxic symptoms in the host. The development of novel methods and systems for the monitoring and detection of foodborne pathogenic bacteria is of great significance for food safety, especially the development of simple, highthroughput and highly sensitive rapid detection techniques. This work proposes a novel aptamer sensor based on reduced graphene oxide (rGO)-AuNPs for the detection of Salmonella in food. Firstly the rGO and AuNPs were modified on the surface of glassy carbon electrode in turn, and then a highly sensitive sensor was made by designing a segment of thiolated aptamer probe that could specifically capture Salmonella. The high electron transport ability of rGO and the advantage of large specific surface area of AuNPs were adopted to achieve signal amplification and improve the detection capability. In the presence of Salmonella, the aptamer traps and immobilizes Salmonella on the surface of the electrode, resulting in a change in the immediate current in the sensor and realizing quantitative detection of Salmonella based on the change in electrical signal. Under the optimized conditions, the response current of the constructed aptamer sensor is linearly related to the logarithmic value of Salmonella concentration, with a linear range of $6 \times 10^{2} \mathrm{cfu} / \mathrm{mL} \sim 6 \times 10^{7} \mathrm{cfu} / \mathrm{mL}$ and a detection limit of $200 \mathrm{cfu} / \mathrm{mL}(\mathrm{S} / \mathrm{N}=3)$. Meanwhile, this sensor has been successfully applied in the detection of Salmonella in pork and beef.
\end{abstract}

Keywords: Foodborne pathogenic bacteria; Aptamer sensor; Reduced graphene oxide; Electrochemical impedance; Label-free detection

\section{$\underline{\text { FULL TEXT }}$}

(C) 2022 The Authors. Published by ESG (www.electrochemsci.org). This article is an open access article distributed under the terms and conditions of the Creative Commons Attribution license (http://creativecommons.org/licenses/by/4.0/). 